\title{
Philosophers should prefer simpler theories
}

\author{
Darren Bradley ${ }^{1}$
}

Published online: 27 October 2017

(C) The Author(s) 2017. This article is an open access publication

\begin{abstract}
Recent years have seen considerable attention paid to the methodology of philosophy. The puzzle is simple-if philosophy is not an empirical discipline, how can one philosophical theory be rationally preferred over another? One answer to this question is that we should apply the theoretical virtues. Foremost among these theoretical virtues is simplicity - so perhaps we should prefer simpler philosophical theories to more complex ones. Huemer (Philos Q 59:216-236, 2009) objects that the reasons to prefer simpler theories in science do not apply in philosophy. I will argue that Huemer is mistaken - the arguments he marshals for preferring simpler theories in science can also be applied in philosophy. Like Huemer, I will focus on the philosophy of mind and the nominalism/Platonism debate. But I want to engage with the broader issue of whether simplicity is relevant to philosophy.
\end{abstract}

Keywords Simplicity $\cdot$ Theoretical virtues $\cdot$ Methodology $\cdot$ Bayesianism

\section{Introduction}

There has been considerable attention paid to the methodology of philosophy in recent years. The puzzle is simple-if philosophy is not an empirical discipline, how can one philosophical theory be rationally preferred over another? One answer to this question is that we should apply the theoretical virtues. Foremost among these theoretical virtues is simplicity—-so perhaps we should prefer simpler philosophical theories to more complex ones. ${ }^{1}$ Huemer (2009) objects that the reasons to prefer

\footnotetext{
${ }^{1}$ Lewis (1986) is a classic source which is explicit about this methodology.

Darren Bradley

bradleydarren@gmail.com

1 Philosophy Department, Leeds University, Woodhouse Lane, LS2 9JT Leeds, UK
} 
simpler theories in science do not apply in philosophy. I will argue that Huemer is mistaken - the arguments he marshals for preferring simpler theories in science can also be applied in philosophy. Like Huemer, I will focus on the philosophy of mind and the nominalism/Platonism debate. But I want to engage with the broader issue of whether simplicity is relevant to philosophy.

I will argue that there are no principled reasons to think that appealing to simplicity in philosophy is any more problematic than appealing to simplicity in science; there are only practical differences that make it difficult to apply simplicitybased arguments in philosophy. These practical issues differ from one case to another. As a result, the work will have to be done on a case-by-case basismetaphilosophy goes hand-in-hand with philosophy. This paper is an attempt to work through some of the details.

There have been several recent discussions about the relevance of simplicity to philosophy, including Bennett (2009), Kriegel (2013), Sider (2013), Tallant (2013), Willard (2014), Thomasson (2015), Huemer (2016), Biggs and Wilson (2017), Paul (2016) and Brenner (2017). However, even those who have defended the use of simplicity in philosophy have not challenged Huemer's arguments. For example, Brenner, defending the use of simplicity in philosophy, merely remarks that '[i]t's not obvious how [Huemer's] arguments [against using simplicity in philosophy] would generalize to debates elsewhere in philosophy, and in metaphysics in particular'. I will argue that even in the areas Huemer focusses on, his arguments do not succeed.

Huemer discusses four arguments for favouring simpler theories-he calls them the Empiricist Argument, the Likelihood Argument, the Numerousness Argument and the Bounded Asymmetry Argument. I want to emphasize that Huemer has performed a valuable service by extracting four clear arguments from a large literature on simplicity (see Huemer's paper for references). My disagreement with Huemer is only over the extent to which they apply to philosophy.

Section 2 discusses the Empiricist Argument, which is based on the success of simple theories. Section 3 discusses the Likelihood Argument, which is based on the fact that complex models are compatible with more possible evidence, and so harder to refute. Section 4 discusses the Numerousness Argument, which is based on the fact that there are more variants of complex models. Section 5 discusses the Bounded Asymmetry Argument, which is based on the fact that there is always a simplest model, but no limit to the possible complexity of models. Section 6 concludes.

\section{The empiricist argument}

Why should scientists prefer simpler theories? The first argument Huemer discusses is based on evidence. The idea is that we have obtained evidence that simpler theories are more likely to be true than complex theories. Huemer suggests the following argument: ${ }^{2}$

\footnotetext{
${ }^{2}$ Compare McAllister (1996), Kuipers (2002), Norton (2003). I think they succumb to the circularity objection below; compare Kelley (2010).
} 
1. Science has been highly successful in identifying truths

2. The best explanation for this is that its methodology is truth-conducive

3. Therefore scientific methodology is probably truth-conducive

4. The appeal to simplicity is a central part of scientific methodology

5. Therefore simplicity is probably a genuine mark of truth p. 218

Huemer argues, I think correctly, that the 1-5 argument is circular. For example, how is (1) to be established? How do we know that science has been successful at establishing truths? Why not think that science appears to identify truths, but is in fact systematically mistaken, perhaps due to an evil demon? We would have to discount this sceptical hypothesis, and it is plausible that we would need to appeal to simplicity (or some such methodological principle) to do so.

Similarly, how is (2) to be established? Why think that the best explanation for the success of science is that its method is truth-conducive? Why not think that the best explanation for the success of science is that an evil demon has arranged things this way? Presumably we need a theory of what makes an explanation good (and best) which says that simpler explanations are good.

So I think Huemer is right to reject the Empiricist Argument as an explanation of why scientists should prefer simpler theories. ${ }^{3}$ This makes it irrelevant to the debate between myself and Huemer, where the question is whether appeals to simplicity in philosophy are more problematic than they are in science.

\section{Likelihood argument}

What Huemer calls the 'Likelihood Argument' is based on the fact that evidence tends to provide greater confirmation to simpler theories. On the standard definition of confirmation (Salmon 1975), E confirms $\mathrm{H}$ iff $\mathrm{P}(\mathrm{ElH})>\mathrm{P}(\mathrm{El}-\mathrm{H})$, and $\mathrm{E}$ disconfirms $\mathrm{H}$ iff $\mathrm{P}(\mathrm{ElH})<\mathrm{P}(\mathrm{El}-\mathrm{H}) .{ }^{4}$ Assuming we have just two theories, call them Simple and Complex, our evidence, E, confirms Simple iff P(ElSimple $)>$ P(ElComplex $)$. Huemer explains the Likelihood Argument' as follows:

The essential point is that typically a simple theory can accommodate fewer possible sets of observations than a complex theory can: the simple theory makes more specific predictions. The realization of its predictions is consequently more impressive than the realization of the relatively weak predictions of a complex theory. p. 221-222

\footnotetext{
${ }^{3}$ Huemer also sets this argument aside because 'the empiricist argument...makes no attempt to explain why simplicity is truth-indicative. Thus even if it persuades sceptics of the value of simplicity, we would still need the sort of explanatory theories considered in the following three subsections' p. 218 I'm not sure we would need such an explanatory theory, but this raises the delicate point of where we should expect explanation to stop, which we need not get into.

${ }^{4}$ See Salmon (1975). Salmon actually discusses $\mathrm{P}(\mathrm{H} \mid \mathrm{E})>\mathrm{P}(\mathrm{H})$, but this is equivalent to the inequality in the text assuming that $0<\mathrm{P}(\mathrm{H})<1$.
} 
For example, suppose we have two types of model, Simple and Complex, where Simple theories predict E1, while Complex theories are compatible with E1 and E2:

Simple

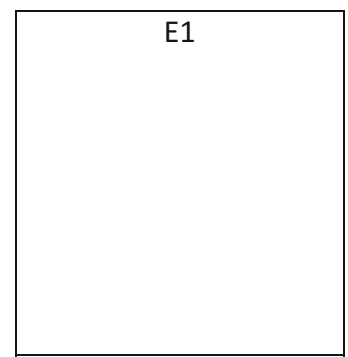

$\mathrm{P}(\mathrm{E} 1 \mathrm{ISimple})=1>\mathrm{P}(\mathrm{E} 1 \mathrm{lComplex})$

Thus E1 confirms Simple

\section{Complex}

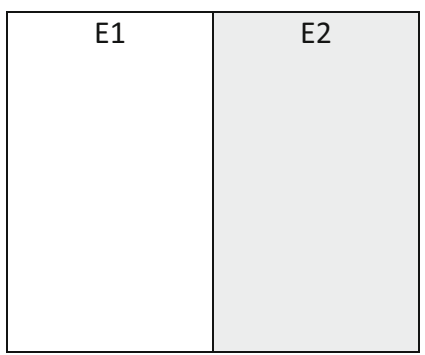

A useful way to think about it is that Simple is confirmed by E1 because it faced the possibility of elimination by $\mathrm{E} 2 .^{5}$

Huemer's main example to demonstrate the idea compares linear $(y=a+b x)$ and parabolic $(y=a+b x+c x 2)$ relationships between two variables. Huemer points out that any three data points are compatible with the family of parabolic curves, but some sets of three points eliminate all linear curves. So linear models face refutation by three data points. If we have three data points that are compatible with linear models then linear models have survived possible refutation, and so are confirmed.

Huemer then argues that:

introducing additional entities into a theory has an effect similar to that of introducing additional adjustable parameters into an equation: suppositions about each of the additional entities can be adjusted to accommodate the data. For example, when Leverrier hypothesized the existence of the planet Neptune to account for observed anomalies in the orbit of Uranus, he had at least two parameters to work with - the mass and orbit of the new planet. The values of these parameters could be adjusted to accommodate the data about Uranus' orbit. In contrast, had Leverrier hypothesized 83 new planets, he would have had 166 adjustable parameters to work with, enabling the accommodation of a far greater range of possible data. p. 222-223

Of course, it is possible that a simple hypothesis is compatible with more evidence than a complex hypothesis. And it is possible that a piece of evidence compatible with both a simple and a complex hypothesis will have higher likelihood given the complex hypothesis. But I want to grant Huemer all the assumptions he wants here, as I don't want to object to the way he uses the concept of simplicity in

\footnotetext{
5 Compare Popper's (1959) falsificationism.
} 
science. Quite the opposite-I endorse the way Huemer uses the concept of simplicity in science, and want to extend the same treatment to philosophy.

So let's apply this to the physicalism/dualism debate. We need to separate two possible pieces of evidence: the causal closure of the physical and psychophysical correlations. I'll argue that in both cases the simpler physicalist/monist theory is confirmed by the evidence.

\subsection{Evidence $=$ causal closure of the physical}

\subsubsection{The argument for physicalism}

Let the evidence be the causal closure of the physical i.e. all physical effects have physical causes. Does this evidence confirm physicalism? I will argue that it does. The reason is that physicalism, a simple theory, is compatible with a narrower range of evidence than dualism, a more complex theory. Specifically, dualism is compatible with the failure of the causal closure of the physical:

Physicalism

Causal closure of the
physical

Dualism

\begin{tabular}{|l|l|}
\hline $\begin{array}{l}\text { Causal } \\
\text { closure of } \\
\text { the physical }\end{array}$ & $\begin{array}{l}\text { No causal } \\
\text { closure of } \\
\text { the physical }\end{array}$ \\
\end{tabular}

The dualist has posited something extra in the universe which, like positing more planets orbiting Uranus, allows a greater range of possible evidence-in this case, the failure of the causal closure of the physical.

It is trivial that physicalism entails the causal closure of the physical; while both substance and property dualism allow (though do not entail ${ }^{6}$ ) that the physical is not causally closed:

$\mathrm{P}($ Causal closure of the physical I Physicalism $)=1>$

$\mathrm{P}$ (Causal closure of the physical I Dualism)

Therefore the causal closure of the physical confirms physicalism.

\footnotetext{
${ }^{6}$ We'll bracket this and come back to it shortly.
} 
To put it another way, the simple physicalist theory is confirmed by the causal closure of the physical because it faced refutation by a violation of the causal closure of the physical.

\subsubsection{Huemer's objections}

First, notice that we don't need physicalism to entail the causal closure of the physical. We get confirmation of physicalism iff:

$\mathrm{P}($ Causal closure of the physical | Physicalism $)>$

$\mathrm{P}$ (Causal closure of the physical I Dualism).

We can now address the following complication: Huemer focusses, not on the causal closure of the physical, but on the apparent causal closure of the physical i.e. the physical world appears to be causally closed. This is an unexpected move. Usually, it is assumed that when we acquire some evidence, we learn something about the world. By focussing on the appearances, Huemer breaks this link. Having flagged this, I don't want to dwell on it, as I don't think there is anything wrong with focussing on appearances. The issue becomes whether:

(I) $\mathrm{P}$ (Apparent causal closure of the physical I Physicalism) $>\mathrm{P}($ Apparent causal closure of the physical I Dualism)?

And (I) is hard to deny. Dualism allows that the physical realm is not causally closed, so will not appear to be causally closed given sufficiently good experiments. ${ }^{7}$ By contrast, physicalism entails that the physical realm is causally closed, so any apparent causal closure of the physical can only be the result of misleading experiments. So the assumption that appearances tend to lead us towards the truth will also lead us to hold that the apparent causal closure of the physical supports physicalism.

Here is a good place to re-visit the point bracketed above that dualism does not entail the failure of causal closure of the physical (let's set aside 'apparent' here to keep the exposition simple). The relation depends on the type of dualism. Regarding substance dualism, Cartesian interactionism says the physical is not causally closed, while Leibnizian pre-established harmony says the physical is causally closed. Regarding property dualism (see Chalmers 1996, 2003), interactionist property dualism says the physical is not causally closed; epiphenomenal and panpsychist dualism say the physical is causally closed:

\footnotetext{
7 For example, we might observe particles in the brain behaving differently from how the laws of nature predict they will behave. In response to the absence of such observations, Eccles (1986) uses quantum indeterminacy to avoid violating causal closure in his dualistic theory, in which consciousness fills the causal gaps. But Chalmers (1996, p. 157) points out that this 'contradicts the quantum-mechanical postulate that these microscopic decisions are entirely random'.
} 


\section{Physicalism}

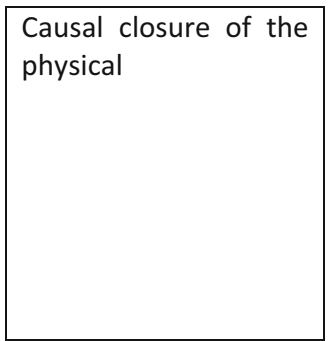

Dualism

\begin{tabular}{|l|l|}
\hline $\begin{array}{l}\text { Causal closure of } \\
\text { the physical. }\end{array}$ & $\begin{array}{l}\text { No causal closure } \\
\text { of the physical. } \\
\text { Pre-established }\end{array}$ \\
Cartesian \\
Epripheny. & interactionism, \\
Panpsychism & Interactionist \\
& property dualism \\
& \\
\hline
\end{tabular}

So the causal closure of the physical eliminates some versions of dualism (e.g. Cartesian dualism) and confirms others (e.g. pre-established harmony). This sort of structure-where a hypothesis is confirmed while some of its sub-hypotheses are disconfirmed-is not unusual, ${ }^{8}$ and does nothing to undermine the Likelihood Argument.

The lesson is that the Likelihood Argument is sensitive to the prior probabilities of the hypotheses at issue. For example, suppose we had ruled out all the varieties of dualism that allow the failure of causal closure of the physical (shaded). Then the remaining versions of dualism would entail the causal closure of the physical, giving the same likelihood as physicalism i.e. 1 .

Returning to Huemer's paper, he offers a number of considerations aimed at undermining (I). I will argue that none succeed. First, Huemer imagines that 'brain scientists find that certain events in the brain cannot be accounted for in terms of standard physical and chemical causes, but could be accounted for by the hypothesis of non-physical mental causes.' p. 232. He then points out that such evidence would not force the abandonment of physicalism:

First, in the imagined scenario, physicalism would not be refuted, for physicalists do not restrict the concept of physical properties to those presently known to physics and chemistry. Hence if science discovered brain events which could not be causally explained by hitherto recognized physical causes, the physicalist could postulate a previously unknown type of physical cause explaining those events. p. 232

Huemer is pointing out that the apparent failure of the causal closure of the physical could be explained by physicalists (by postulating new physical causes), which undermines:

$\mathrm{P}($ Apparent causal closure of the physical I Physicalism $)=1$.

Huemer is surely right about this. But we've seen that the physicalist does not need such a strong assumption. The physicalist only needs:

\footnotetext{
${ }^{8}$ For example, the evidence that Bob has a furry pet confirms that he has a dog, but disconfirms the subhypothesis that he has a Peruvian hairless dog (see Kotzen 2012).
} 
$\mathrm{P}($ Apparent causal closure of the physical I Physicalism $)>$

$\mathrm{P}$ (Apparent causal closure of the physical I Dualism)

whereas Huemer's position that the evidence fails to confirm physicalism needs:

$\mathrm{P}($ Apparent causal closure of the physical I Physicalism $) \leq \mathrm{P}$ (Apparent causal closure of the physical I Dualism)

And as we saw above, this inequality is implausible.

Huemer offers a second objection to the argument for physicalism:

the evidence which would favour physicalism has not in fact been acquired...In the present case, the evidence which would favour physicalism has not been gathered, because scientists have not discovered a complete causal explanation of all changes in the brain and all human behaviour: that is, it is not yet known whether the observable facts will fall within the range allowed by the theory. p. 232-233

Two responses. First, Huemer seems to have forgotten his own move of focussing on the apparent causal closure of the physical. It may not yet be known that the physical is causally closed, but it does appear that it is. And this evidence confirms physicalism.

Second, the question is not whether we have evidence for physicalism, but whether the reasons to prefer simpler theories in science also apply in philosophy. Answers to this question do not depend on what evidence has actually been found, they depend on what would be confirmed by possible evidence. And I have argued that the causal closure of the physical would confirm physicalism.

\subsection{Evidence $=$ psychophysical correlations}

\subsubsection{The argument for physicalism}

Next, let the evidence be psychophysical correlations i.e. each type of mental state is correlated one-to-one with a type of physical state. And consider the hypothesis of type-physicalism: for every actually instantiated mental property $\mathrm{F}$, there is some physical property $\mathrm{G}$ such that $\mathrm{F}=\mathrm{G} .{ }^{9}$ Would psychophysical correlations confirm type-physicalism? Huemer says no; I say yes.

Here's the likelihood argument for type-physicalism. Type-physicalism entails that each type of mental state is correlated with a type of physical state, whereas the more complex dualist theory leaves open the possibility that there is no correlation between physical and mental states:

$\mathrm{P}($ Psychophysical correlations | Type-physicalism $)=1>$

P(Psychophysical correlations I Dualism)

Therefore the evidence confirms type-physicalism.

\footnotetext{
${ }^{9}$ See Stoljar (2016). We'll stipulate that G is relatively homogenous at the physical level, ruling out multiply realizable physical properties which would not be in the spirit of type-physicalism.
} 
Type-physicalism

\begin{tabular}{|l|}
\hline Psychophysical \\
correlations \\
\end{tabular}

Dualism

\begin{tabular}{|l|l|}
\hline Psychophysical & No psychophysical \\
correlations & correlations \\
& \\
\hline
\end{tabular}

Again, the extra stuff the dualist posits allows a greater range of evidence. The simple type-physicalist theory is confirmed by psychophysical correlations because it faced refutation by an absence of psychophysical correlations.

(It is worth mentioning a similar argument for token physicalism. Dualism allows the failure of supervenience. That is, dualism allows one-many relations between physical and mental states e.g. c-fibres are related to pain in some instances, joy in other instances and no mental state in further instances- the latter being a zombie case (Chalmers 1996). Token physicalism entails supervenience, ruling out such one-many relations. So supervenience confirms token physicalism.

Token-physicalism

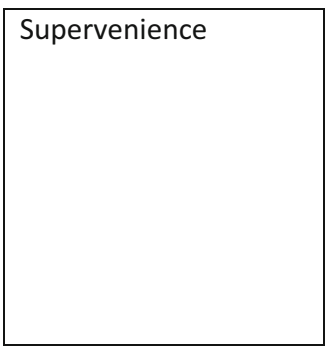

Dualism

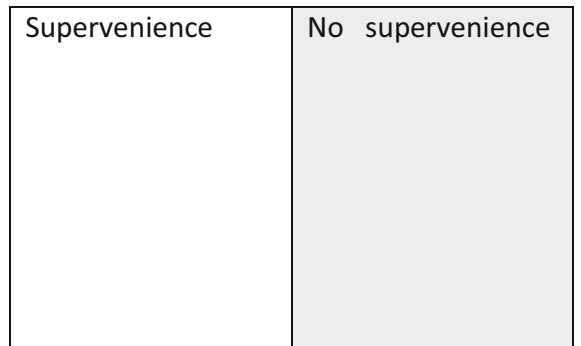

$\mathrm{P}($ Supervenience | Token-physicalism $)=1>$ P(Supervenience I Dualism)

Therefore supervenience confirms token-physicalism)

\subsubsection{Huemer's objections}

Huemer only explicitly discusses type-physicalism, and objects that type-physicalism can allow a wide range of possible evidence, including non-actual psychophysical correlations:

The physicalist's adjustable parameters are assumptions about psychophysical identities or supervenience relations. The physicalist can adjust assumptions 
about what sort of physical or functional states mental states supervene on, so as to accommodate the observed psychophysical correlations. Any set of supervenience relations is compatible with physicalism as such; so physicalism too is virtually guaranteed to be consistent with the data. p. 232

But Huemer has misidentified the evidence. He assumes the evidence is the specific psychophysical correlations i.e. that pain is correlated with c-fibres firing rather than with d-fibres firing. But it's not the specific psychophysical correlations that confirm type-physicalism-it's the fact that there are any psychophysical correlations at all! That is, it's that pain is correlated with c-fibres firing rather than not correlated with any physical property at all. This is the evidence that is entailed by type-physicalism but not by dualism.

Huemer offers a couple of further objections. He considers the following conditional, which he takes to be a new way of putting the argument for physicalism: if physicalism could be refuted by the failure of concerted efforts to identify robust type-type correlations then the discovery of type-type correlations would confirm physicalism.

He responds by rejecting the antecedent, saying that

the imagined evidence [the failure of concerted efforts to identify robust typetype correlations] would not refute physicalism, for most physicalists already embrace the thesis of multiple realizability; thus they are not committed to the existence of type-type correlations between mental and physical states. p. 233

This is a puzzling response. First, one cannot reject a conditional by rejecting the antecedent, and it is the conditional that is at issue. Setting this aside, Huemer shifts to token physicalism on the grounds that most physicalists are token-physicalists. But this is not relevant. What's relevant is whether type-physicalism could be refuted by the failure of concerted efforts to identify robust type-type correlations. And surely it could be (or at least it could be disconfirmed, which is what's at issue).

Huemer then objects that 'even if we accept that [type] physicalism would be refuted by the failure to find type-type correlations..., this point does not favour [type] physicalism over dualism until the type-type correlations are found'. p. 233

But the question isn't whether we have evidence for type-physicalism; it's whether evidence compatible with it would confirm type-physicalism. Huemer seems to have switched from the general question of whether philosophers should prefer simpler theories to the specific question of whether type-physicalism is true.

\subsection{Other debates}

To what extent does this generalize to other debates in philosophy? The Likelihood Argument can only apply when the competing theories predict different evidence. In many cases philosophical debates agree on the evidence so the Likelihood Argument won't apply. Nevertheless, I think there are some philosophical debates where it is plausible that evidence is relevant, and where the Likelihood Argument applies. 
Let's consider the nominalism versus Platonism debate, which Huemer discusses. Let Platonism be the theory that posits objects and properties; let nominalism be the theory that posits only objects. Nominalism is the simpler theory, so could evidence confirm it? For nominalism to be confirmed by the Likelihood Argument, there must have been possible evidence that would have refuted nominalism that has failed to be found. But what possible evidence could have refuted nominalism? Huemer argues that there is none-either nominalism can account for our actual evidence, in which case it 'is consistent with all possible data [evidence]' (p. 234) or nominalism cannot account for our actual evidence, in which case it is refuted.

But the first disjunct is problematic. It could be that nominalism can account for our actual evidence, but is inconsistent with other possible evidence. (Huemer doesn't consider this possibility.)

For example, we might think that nominalists are committed to paraphrasing true sentences that quantify over properties. Suppose actual true sentences that quantify over properties can be paraphrased, but there are possible worlds with true sentences that cannot be paraphrased. Then nominalism is inconsistent with the possible evidence in these unparaphrasable worlds.

There might be other possible evidence that could refute nominalism, even if it takes a bit more imagination. Schaffer (2003) defends the possibility of lone properties. That is, although properties come in clusters (this page has mass, shaper, colour etc.), there is no (necessary) reason why 'the mass of this page [doesn't] break free, and wander off by itself, leaving its whiteness and smoothness behind' p. 125. If we could observe such a lone property it would presumably refute nominalism. As we have not, nominalism is confirmed.

Of course, one might reject such a possibility, or deny that we could obtain the evidence suggested, but the point is that there seems to be possible evidence that would refute nominalism. ${ }^{10}$ The more general point is that there seems to be nothing about philosophy as such that prevents us from applying the Likelihood Argument.

It seems that the strategy of trying to find the simplest theory that is compatible with our evidence applies to other topics. For example, Harman (1977) denies that there are objective moral facts on the grounds that they are not needed to explain our moral judgments. Call this relativism. In this case our judgments are taken to be evidence. Could alternative judgments have refuted (or disconfirmed) relativism? If so, the argument can be understood as saying that our moral judgments could have disconfirmed relativism, and as they have not, relativism is confirmed. And Tallant (2013) uses our judgment that ['dinosaurs exist' is false] as evidence for Presentism. If our judgments are counted as evidence in this way, there seems to be no limit to the possible application of the Likelihood Argument. ${ }^{11}$

In this section I argued that the Likelihood Argument for simpler theories can apply in philosophy. But one characteristic feature of philosophy is that evidence does not seem relevant in the same way it is in science, so the Likelihood Argument

\footnotetext{
${ }^{10}$ Perhaps lone properties are negatively conceivable, meaning roughly that although we cannot positively imagine it, we don't get a contradiction if we try and we cannot rule it out a priori (Chalmers 2002).

11 I am sceptical that our judgments should count as evidence here, but that is a different story.
} 
might be less important in philosophy than in science. We need to turn to nonevidence based arguments for simplicity-I turn to these for the rest of the paper and argue that they can apply in philosophy.

\section{Numerousness argument}

The Numerousness Argument seeks to show that more complex theories have lower prior probability. The strategy is to first group theories according to degree of complexity i.e. a group of very simple theories, a group of less simple theories, and so on. Then assign to each equivalence class of equally complex theories an equalor at least not wildly different-prior probability. Assuming there are more types of complex theory than types of simple theory, that same prior probability must be shared around more theories in the complex groups than around the simpler groups, so each complex theory ends up with a lower prior. ${ }^{12}$ In this diagram, offered by Huemer, the world has an equal probability of being simple or complex (1/2), but each complex theory ends up with a lower probability (of 1/10 rather than 1/6):

\begin{tabular}{|c|c|c|c|c|c|}
\hline Simple (1/2) & \multicolumn{2}{|l|}{$1 / 6$} & \multicolumn{2}{|l|}{$1 / 6$} & $1 / 6$ \\
\hline Complex (1/2) & $1 / 10$ & $1 / 10$ & $1 / 10$ & $1 / 10$ & $1 / 10$ \\
\hline
\end{tabular}

As Huemer puts it:

There is some reason for thinking that ontologically complex theories are in fact more numerous than ontologically simple theories. The positing of new entities generally allows multiple theories concerning the nature of those entities; consequently, the more entities one posits, the more theories one can construct about those entities. p. 220-221

\subsection{Philosophy of mind}

Let's see if we can apply this to the philosophy of mind. Consider three theories:

Physicalism: There exists only a physical substance with only physical fundamental properties

Idealism: There exists only a mental substance with only mental fundamental properties

\footnotetext{
12 Three points by way of clarification. First, as this is an a priori argument, it inherits any worries about prior probabilities one might have. But, second, it doesn't commit us to favouring simplicity over complexity a priori. It only commits us to favouring specific simple theories over specific complex theories a priori. So we need not think the world is more likely to be simple than complex. Third, theories that have a relatively high prior may well end up with a low posterior once evidence comes in.
} 
Neutral monism: There exists only a neutral substance that has both mental and physical fundamental properties

The two relevant groups of theories are:

Monism: There exists exactly one type of substance

Dualism: There exists exactly two types of substance

Let's assign monism and dualism an equal prior probability of $1 / 2$ each. The argument would then proceed that there are more dualistic theories than monistic theories. As the

$1 / 2$ probability must be spread over more dualistic theories than monistic theories, each dualistic theory ends up with a lower prior.

However, Huemer argues that there are not more dualistic theories than monistic theories. Huemer claims that:

[Monism] belongs to the larger class, since the class of monistic theories has at least three members (physicalism, idealism and neutral monism), while the class of dualistic theories of the mind-body relation has only one member (dualism). P. 231

It seems that Huemer is considering only the following theories:

Monistic theories: 1) physicalism 2) idealism and 3) neutral monism

Dualistic theories: 1) physical substance + mental substance

But these are not the only dualistic theories. With these three monistic theories, we should allow three dualistic theories:

Dualistic theories:

1) physical substance + mental substance

2) physical substance + neutral substance

3) mental substance + neutral substance

We get the same number of monistic and dualistic theories (three), so no argument for monism yet. But as soon as we increase the number of types of substance, the number of dualistic theories rapidly rises. With four types of substance there are four monistic theories and six dualistic theories. Five types of substance allows five monistic theories and ten dualistic theories. A priori, all of these types of substance might exist, so they must all be included among the possibilities over which the prior probability is distributed. The result will be that a priori there will be many more dualistic theories, and so the Numerousness Argument can be applied.

Here is a diagram for four types of substance. Set aside all possibilities other than monism and dualism, with each assigned a probability of $1 / 2$. The four monistic 
theories therefore get a probability of $1 / 8$ and the six dualistic theories get a probability of $1 / 12$ :

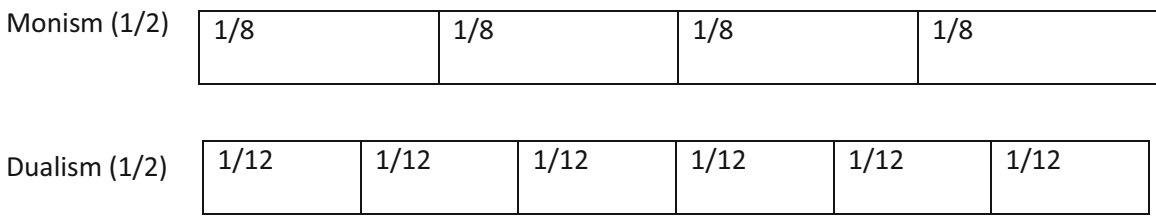

So each (simple) monist theory gets a higher probability than each (complex) dualist theory.

Perhaps the objection is that there are no plausible candidates for the extra types of substance. But remember the Numerousness Argument is about the distribution of priors, so everything epistemically possible a priori is relevant. And surely it is epistemically possible a priori that there are biological substances, chemical substances and others? And perhaps abstract objects are another substance. Indeed perhaps different types of abstract object are different substances e.g. numbers, propositions etc. And what about more exotic possibilia like angels and Greek gods? And if we switch from substance dualism to property dualism it is very plausible that there are many possible types of fundamental property e.g. physical, phenomenal, intentional, biological, chemical, sociological, normative etc. ${ }^{13}$

\subsection{Other debates}

Can this Numerousness argument be applied to other areas of philosophy? I think a preference for positing fewer types of objects can be found in the background of many debates, and is so widely accepted that it is easy to overlook.

Start with nominalism versus Platonism. It is natural to conceptualize nominalism as a theory that only posits one category — objects — and Platonism as a theory that posits (at least) two categories-objects and properties. So, with a slight extension of the usual terminology, nominalism is a variety of monism and Platonism is a variety of dualism. The analysis above can then be applied-simpler theories like nominalism have higher prior probabilities.

Huemer considers this but complains:

This would fail to deliver the result required by the nominalistic appeal to simplicity, since again there are not more dualistic theories than monistic theories on this issue. p. 231

The problem is that there is only one dualistic theory-Platonism-and two monistic theories - that only objects exist and that only properties exist.

This is the same objection Huemer gives in the philosophy of mind case. Huemer is right when there are only two possible categories. But why would we be limited to two possible categories a priori? A priori, there are surely an indefinite number of categories. Once we remember that the argument applies to priors, and don't

\footnotetext{
13 Trialism has been defended by Cottingham (1985). Thanks to Ben Blumson for the reference.
} 
artificially restrict the range of prior possibilities, the Numerousness Argument favouring simpler theories goes through.

Another natural candidate for the Numerousness Argument is the debate about whether objects are fundamental or are constituted by bundles of properties. The bundle theory, like nominalism, posits only one category; it posits properties rather than objects. But what's so good about one-category theories? They are good if we have a preference for simpler theories. The Numerousness Argument gives us a reason for this preference. ${ }^{14}$

The debate about the existence of numbers has a similar form. It seems to be taken for granted that if we can avoid positing numbers, the nominalist wins (Field 1980). But why should this be? Presumably because we have a preference for an ontology with fewer types of object, and the Numerousness Argument explains why.

Debates about material objects also have this structure. The nihilist posits only fundamental particles like quarks, while common sense allows composite objects like tables. One of the main arguments for nihilism is a preference for a simpler ontology (Schaffer 2007, Cameron 2008). We could understand the nihilist as being committed to only one type of object-simple objects-while common sense is also committed to composite objects. The preference for a simpler ontology is explained by the Numerousness Argument.

For an example outside metaphysics, Finlay and Schroeder (2017) say that simplicity plays a role in the debate between reasons internalism versus externalism:

The idea behind this reasoning is that if we have to agree that some reasons depend on desires, then we should give serious consideration to the theory according to which all reasons do, as being simpler...than the theory according to which some reasons derive from our desires but others do not.

The theory according to which all reasons depend on desires could be thought of as a monistic theory, the theory that reasons depend on desires and morality a dualistic theory, the theory that reasons depend on desires, morality and prudence a trialistic theory, and so on.

And, switching from substances to properties, positing non-natural moral properties (Moore 1903) is analogous to positing non-natural mental properties. In both cases, the question is whether we have one type of fundamental property or two, and it is widely assumed that by default we should prefer the possibility with only one fundamental type of property. The Numerousness Argument promises to explain why.

There is a limitation to this argument however. It will only apply when one theory posits strictly more complexity than its competitor, and things are often not so straightforward. Consider the debate about the foundations of modality:

On what we'll call the Lewisian hypothesis, facts about modality are grounded on facts about concrete worlds, and are best stated by quantifying over these worlds. $^{15}$

\footnotetext{
${ }^{14}$ Paul (2016) explicitly defends a bundle theory on the grounds that it is a one-category theory.

15 Lewis (1986).
} 
On what we'll call the Priorian hypothesis, facts about modality are primitive, and are best stated using primitive operators such as possibly. ${ }^{16}$

There is a distinction between ontological (things in the world) and ideological (concepts needed to describe the world) simplicity; and ontological simplicity then divides into quantitative (number of things) and qualitative (number of types of thing) simplicity. ${ }^{17}$ The disagreement between Lewisian and Priorian views is plausibly rooted in disagreement about how to weigh up these different types of simplicity.

The Priorian hypothesis scores well on qualitative and quantitiative ontological simplicity. The ontological cost of the Priorian hypothesis is zero, as it posits no new entities, nor types of entity. The cost comes in ideological complexity, as the hypothesis posits primitive modal concepts.

The Lewisian hypothesis scores well on qualitative ontological simplicity and ideological simplicity. The qualitative ontological cost of the Lewisian hypothesis is zero, ${ }^{18}$ as it posits only types of thing that we already take to exist, namely concrete worlds. The Lewisian hypothesis is also ideologically simple, as we don't need primitive modal concepts. The cost comes in quantitative ontological complexity, as the hypothesis posits a possibly infinite number of concrete worlds. But Lewis thought this cost was small.

The moral is that even if we agree that simpler theories are to be preferred, we still have to work out which types of simplicity matter and how they should be weighed against each other. The Numerousness Argument gives us a start, but there is a lot more still to do.

\section{Bounded Asymmetry}

The Bounded Asymmetry argument starts from the fact that the complexity of theories is unbounded in one direction only. Huemer writes:

for any given phenomenon, there is a simplest theory (allowing ties for simplest), but no most complex theory of the phenomenon: however complex a theory is, it is always possible to devise a more complicated one. This is most easily seen if we take a theory's complexity to be measured by the number of entities that it posits: one cannot posit fewer than zero entities, but for any number n, one could posit more than $n$ entities. Similar points hold for other measures of complexity, such as the number of parameters in an equation. p. 219

\footnotetext{
16 Prior (1957).

17 And perhaps ideological simplicity divides into quantitative and qualitative; see Cowling (2013).

18 So Lewis claimed. A problem Lewis did not consider is that these possible worlds contain all sorts of weird and wonderful types of things that do not actually exist (see Melia 1992). Thanks to a referee for pointing this out. On the other hand, the Lewisian can use possible worlds to define propositions, properties and other things (Lewis 1986, ch. 1) that the Priorian has to account for in some other way.
} 
Now note that the total probability across all possible hypotheses must sum to 1 . As there are more complex theories than simple ones, theories must get diminishing probability as their complexity increases.

Huemer claims that this argument applies in science, but not in philosophy:

The argument...does not apply to the physicalism/dualism debate, because physicalism and dualism are not naturally viewed as successive steps in some infinite hierarchy of theories. P. 230

But the opposite seems to be true. Physicalism is a theory with one type of substance; dualism is a theory with two types of substance; next comes three types of substance; then four, etc. Is there any reason to think there couldn't be an infinite number of types of substance?

Huemer doesn't say much to explain his position. He just says 'The fundamental question for physicalists and dualists is not 'How many kinds of state are there?', but 'What is the relationship between the mental and the physical?' p. 230

In response, we can grant that the fundamental question for physicalists and dualists is 'What is the relationship between the mental and the physical?' Nevertheless, they end up disagreeing on what kinds of state there are, so the prior probability of the existence of each kind of state is relevant to what we should believe. Compare: a fundamental question for physicists is 'What are the fundamental laws of nature?'. Nevertheless, the prior probability of any proposed laws are relevant to what we should believe.

Similar considerations apply to the nominalism versus realism debate. Huemer applies the same objection-that the debate is only about the relation between objects and properties - so there are only two things that are relevant. But although philosophers focus on this debate, there is no a priori reason to rule out an infinite number of weird and wonderful types of thing. Only our imaginations seem to prevent us from indefinitely expanding the list containing, numbers, propositions, tropes fictional people, descriptive properties, normative properties, angels and Greek gods. If so, the Boundary Asymmetry Argument suggests that each simpler theory gets higher prior probability. I won't go through all the other examples of the last section, but it seems natural to extend this argument to other controversies in philosophy.

\section{Conclusion}

I have argued that the reasons Huemer marshals for preferring simpler theories in science also apply in philosophy. Physicalism is confirmed by the causal closure of the physical and by psychophysical correlations. Huemer's objections to the Numerousness and Bounded Asymmetry arguments seem to arise because he focusses on only the theories that are live contenders in contemporary philosophy. But as these are both a priori arguments, we should not limit the relevant theories in this way.

The overall result is that we have been able to apply the arguments Huemer discusses to philosophical controversies. So there seems to be no principled reason 
why the considerations applied in scientific controversies should not also be applied in philosophical controversies.

However, we have also found two limitations of the extent to which these arguments can be applied in philosophy. First, the Likelihood Argument only applies when one theory is compatible with strictly more evidence than its competitors. The limitation here comes from the fact that many philosophical theories do not disagree with each other about the evidence, so the Likelihood Argument will not apply. Second, the Numerousness Argument and Boundary Asymmetry Argument only apply when one theory describes a world that is strictly more complex than its competitors. This will apply in some cases, but not in others. Different types of simplicity will have to be traded off, and as it stands there is no clear method for how this should be done. But these are all questions of detail that will vary from one case to another-we have found no principled reason why simplicity considerations should not be applied in philosophy.

Acknowledgements Thanks to Robbie Williams for discussion and comments on an earlier draft and to two referees from this journal. This work received funding from the European Union's Horizon 2020 research and innovation programme under the Marie Sklodowska-Curie Grant Agreement No. 656441.

Open Access This article is distributed under the terms of the Creative Commons Attribution 4.0 International License (http://creativecommons.org/licenses/by/4.0/), which permits unrestricted use, distribution, and reproduction in any medium, provided you give appropriate credit to the original author(s) and the source, provide a link to the Creative Commons license, and indicate if changes were made.

\section{References}

Bennett, K. (2009). Composition, colocation, and metaontology. In: D. J. Chalmers, D. Manley \& R. Wasserman (Eds.), Metametaphysics: new essays on the foundations of ontology (p. 38). Oxford University Press.

Biggs, S., \& Wilson, J. (2017). The a priority of abduction. Philosophical Studies, 174(3), 735-758.

Brenner, A. (2017). Simplicity as a criterion of theory choice in metaphysics. Philosophical Studies, 174(11), 2687-2707.

Cameron, R. P. (2008). Truthmakers and ontological commitment: or how to deal with complex objects and mathematical ontology without getting into trouble. Philosophical Studies, 140(1), 1-18.

Chalmers, D. J. (1996). The conscious mind. Oxfords: Oxford University Press.

Chalmers, D. J. (2002). Does conceivability entail possibility? In: T. S. Gendler, J. Hawthorne (Eds.), Conceivability and Possibility (pp. 145-200). Oxford: Oxford University Press.

Chalmers, D. J. (2003). Consciousness and its place in nature. In: S. Stich, F. Warfield (Eds.), Blackwell Guide to the Philosophy of Mind (pp. 102-142). Oxford: Blackwell.

Cottingham, J. (1985). Cartesian trialism. Mind, 94(374), 218-230.

Cowling, S. (2013). Ideological parsimony. Synthese, 190(17), 3889-3908.

Eccles, J. C. (1986). Do mental events cause neural events analogously to the probability fields of quantum mechanics? Proceedings of the Royal Society of London B, 227, 411-428.

Field, H. (1980). Science without numbers. Malden, Mass.: Blackwell.

Finlay, S., \& Schroeder, M. (2017). Reasons for action: Internal vs. external. In E. N. Zalta (ed.), The stanford encyclopedia of philosophy (Fall 2017 Edition). https://plato.stanford.edu/archives/ fall2017/entries/reasons-internal-external/.

Harman, G. (1977). The nature of morality. Oxford University Press.

Huemer, M. (2009). When is parsimony a virtue? Philosophical Quarterly, 59, 216-236. 
Huemer, M. (2016). Serious theories and skeptical theories: Why you are probably not a brain in a vat. Philosophical Studies, 173(4), 1031-1052.

Kelly, T. (2010). Hume, norton and induction without rules. Philosophy of Science, 77(December), 754-764.

Kotzen, M. (2012). Dragging and confirming. Philosophical Review, 121(1), 55-93.

Kriegel, U. (2013). The epistemological challenge of revisionary metaphysics. Philosophers' Imprint, $13(12), 1-30$.

Kuipers, T. (2002). Beauty: A road to truth. Synthese, 131, 291-328.

Lewis, D. (1986). On the purality of worlds. Oxford: Blackwell Publishers.

McAllister, J. W. (1996). Beauty and revolution in science. Ithaca: Cornell University Press.

Melia, J. (1992). A note on Lewis's ontology. Analysis, 52(3), 191-192.

Moore, G. E. (1903). Principia Ethica. Dover Publications.

Norton, J. (2003). A material theory of induction. Philosophy of Science, 70, 647-670.

Paul, L. A. (2016). A one category ontology. In J. A. Keller (Ed.), Freedom, metaphysics, and method: Themes from van Inwagen. Oxford: Oxford University Press.

Popper, K. (1959). The logic of scientific discovery, translation of Logik der Forschung. London: Hutchinson.

Prior, A. N. (1957). Time and modality. Oxford: Oxford University Press.

Salmon, W. C. (1975). Confirmation and relevance. Minnesota Studies in the Philosophy of Science, 6, 3-36.

Schaffer, J. (2003). The problem of free mass: Must properties cluster? Philosophy and Phenomenological Research, 66(1), 125-138.

Schaffer, J. (2007). From Nihilism to Monism. Australasian Journal of Philosophy, 85(2), 175-179.

Sider, T. (2013). Against parthood. Oxford Studies in Metaphysics, 8, 237.

Stoljar, D. (2016). Physicalism. In E. N. Zalta (ed.), The stanford encyclopedia of philosophy (Spring 2016 Edition). http://plato.stanford.edu/archives/spr2016/entries/physicalism/.

Tallant, J. (2013). Quantitative parsimony and the metaphysics of time: Motivating presentism. Philosophy and Phenomenological Research, 87(3), 688-705.

Thomasson, A. (2015). Ontology made easy. Oxford: Oxford University Press.

Willard, M. B. (2014). Against simplicity. Philosophical Studies, 167, 165-181. 